\title{
Conflitos de classes, defesa de direitos e Serviço Social
}

\author{
Class conflicts, defense of rights and Social Work \\ JAime Hillesheim ৫ \\ Universidade Federal de Santa Catarina, Florianópolis, SC, Brasil.
}

\author{
8003
}

RESUMO - A partir de pressupostos marxianos e marxistas, em particular, das contribuições de György Lukács sobre o direito como ideologia, procura-se, aqui, instigar a reflexão sobre os desafios teóricos e práticos do serviço social no tempo presente, para que a profissão não veja seu projeto ético-político capitular em face da intensificação da ofensiva do capital sobre o trabalho. No presente artigo são abordadas, essencialmente, as contradições do trabalho do assistente social na defesa e ampliação dos direitos em face da lógica própria da sociabilidade burguesa. São situados os desafios impostos pelos limites dessa sociabilidade que exigem, para o seu enfrentamento, a compreensão da teoria social crítica, haja vista seu potencial de subsidiar o trabalho profissional em consonância com os valores e princípios constantes do projeto supracitado.

Palavras-chave: Luta de classes. Direitos. Emancipação Humana. Serviço social.

ABSTRACT - Based on Marxian and Marxist assumptions, in particular, the contributions of György Lukács to the law as ideology, we try to elicit reflection on the current theoretical and practical challenges to social service to prevent the profession from seeing its ethico-political project capitulate in view of the intensification of the capital offensive against labor. In this paper, the contradictions of the social worker's work in defending and extending rights vis-a-vis the own logic of bourgeois sociability are discussed. We address the challenges imposed by the limits of such sociability, which require, to be faced, an understanding of critical social theory, given its potential to contribute to professional work in line with the values and principles of the aforementioned project.

Keywords: Class struggle. Rights. Human emancipation. Social work. 


\section{Introdução}

s abordagens mais críticas sobre a ideologia, notadamente as que se localizam no espectro teórico marxista, estão marcadas pela ideia de inversão da realidade. Essa inversão, a nosso ver, está sempre voltada para a amenização dos conflitos decorrentes dos antagonismos de classes. Isso denota a importância do debate sobre as funções do complexo do direito no processo de desenvolvimento do ser social e que o inscreve dialeticamente no campo das ideologias. E, pela atuação dos profissionais de serviço social na luta pela criação, defesa e ampliação dos direitos sociais, esses dois complexos se comunicam quando da atuação dos seus agentes no âmbito da emancipação política.

No caso paricular do serviço social, sua legitimidade está intimamente relacionda com sua capacidade de fazer com que os usuários dos serviços os quais operacionaliza, individual ou coletivamente, sejam alcançadas pelo acervo de direitos pactuado no âmbito da sociabilidade burguesa. Desse ponto de vista, poderíamos dizer que o trabalho profissional - com seus fundamentos teórico-metodológicos e éticopolíticos - ganha concretude no campo das políticas sociais, cujos formas e conteúdos são determinados pela dinâmica das classes. As políticas sociais são mediações para que os trabalhadores (usuários dos serviços sociais) tenham acesso à parte da riqueza por eles produzida, como desdobramento das desigualdades geradas pela forma social regida pelo capital, cuja dinâmica foi devidamente explicitada por Marx ao desenvolver sua teoria do valor. $\mathrm{E}$, em virtude dos antagonismos existentes entre capital e trabalho, essa forma social não pode prescindir de mecanismos que busquem dar legitimidade aos processos que garantam a produção constante e crescente de um excedente econômico a ser apropriado privativamente pelas classes detentoras dos meios de produção. Nesse sentido, tanto o serviço social quanto o direito e a estrutura jurídico-legal existente desempenham papéis correlatos: contruibuem para a resolução de conflitos na sociedade de classes.

Nosso propósito neste artigo é problematizar, a partir de pressupostos de György Lukács (2013), a relação entre o serviço social e o complexo do direito e, mais especificamente, colocar luzes nos discursos sobre os direitos assimilados pelos assistentes sociais. Pensamos que essa problematização é bastante oportuna, tendo em vista a conturbada realidade vivida pelos trabalhadores brasileiros em face do avanço do capital sobre suas conquistas históricas no âmbito dos chamados direitos sociais. Em seu conjunto, as diversas ofensivas em curso constituem não somente propostas de contrarreformas, mas, mais do que isso, pretendem inaugurar uma nova forma de Estado, fundada em uma variação neoliberal ainda mais radical e extrema, depois do fracasso das proposições de cunho neodesenvolvista pautadas na conciliação de classes levadas a cabo nos períodos dos governos trabalhistas no Brasil (2003-2016). Nesta nova estrutura estatal, não cabem, por certo, as necessidades da classe trabalhadora, para as quais as respostas formuladas se afastam enormemente das perspectivas de universalização dos direitos sociais, tratados pelas classes dominantes como privilégios descabidos que obstam o crescimento econômico do País.

Com o advento do golpe parlamentr-jurídico-midiático de 2016 e com a ascensão das forças políticas ultraconservadoras representadas pelo Presidente da República Jair Bolsonaro, os trabalhadores têm se deparado, ainda que não tenham consciência do tamanho da ofensiva em curso, com duros ataques ao acervo de direitos conquistado pelas históricas lutas políticas. A programática adotada pelo então governo golpista de Michel Temer era a de quem era sabedor das condições impostas pela burguesia nacional para sua permanência temporária no poder. Em face disso colocou em prática um projeto que permitiu rápida e essencialmente: criar e potencializar as estratégias de uso do excedente econômico apropriado pelo Estado em favor do capital, intensificar ações que objetivam o apassivamento das classes trabalhadoras e instituir um padrão de condições objetivas que permitam ampliar os processos de superexploração que se apresentasse como a única alternativa para o conjunto dos trabalhadores. Tudo agravado pela polarização política que dividiu o País após o golpe de 2016 e que culminou nos resultados eleitorais de 2018, fato que avalizou a continuidade e intensificação dos processos de supressão de direitos conquistados pela sociedade brasileira, especialmente a partir dos períodos que se seguiram à chamada redemocratização.

Esta realidade impõe ao serviço social, no contexto das lutas por dirietos, a ultrapassagem de respostas profissionais endógenas, de maneira que estas lutas se articulem com a luta pela criação das condições 
objetivas e subjetivas para a superaração da ordem capitalista. Não se trata de abstrair os constrangimentos que a profissão enfrenta no mercado de trabalho, mas de fazer das lutas por direitos uma tática que não esteja dissociada da estratégia de construção de uma outra sociabilidade. Sem ter no horizonte esta necessária articulação, a tendência é que o serviço social brasileiro capitule diante da atualização da política de conciliação pelo alto - historicamente adotada no Brasil diante de crises econômico-políticas -, assimile o transformismo e/ou os retrocessos propostos e construa parâmetros de atuação limitados às possibilidades da realidade posta.

Neste artigo procuraremos trazer algumas reflexões teóricas sobre o complexo do direito à luz das formulações lukacsianas, bem como problemtizar questões que se colocam no âmbito do serviço social em face do compromisso ético e polítco que este tem assumido na defesa da manutenção e ampliação dos direitos sociais, no contexto da sociedade de classes.

\section{A função ideológica do complexo do direito na sociedade de classes}

Tomando como pressuposto a tese defendida por Marx na qual ele afirma que da base econômica surge uma superestrutura político-ideológica, György Lukács (2013) - filósofo húngaro de destaque no cenário intelectual marxista do século XX - adverte que é errado entender a ideologia como representação do pensamento de pessoas singulares. Para o autor:

Antes de qualquer coisa: enquanto uma ideia permanecer o produto do pensamento ou a alienação do pensamento de um indivíduo, por mais que seja dotada de valor ou de desvalor, ela não pode ser considerada como ideologia. Nem mesmo a difusão social relativamente mais ampla tem condições de transformar um complexo de ideias diretamente em ideologia. Para que isso aconteça, é necessária uma função determinada com muita precisão, a qual Marx descreve de modo a fazer uma diferenciação precisa entre as revoluções materiais das condições econômicas de produção e as 'formas jurídicas, políticas, religiosas, artísticas ou filosóficas, em suma, ideológicas, nas quais os homens se conscientizam desse conflito e o enfrentam até solucioná-Io' (LUKÁCS, 2013, p. 464).

Na perspectiva de Lukács (2013, p. 464), "a ideologia é sobretudo a forma de elaboração ideal da realidade que serve para tornar a práxis social humana consciente e capaz de agir". E, de acordo com o mesmo autor, a ideologia "[...] tem origem imediata e necessariamente no hic et nunc social dos homens que agem socialmente em sociedade". Nesse sentido, "[...] toda reação humana ao seu meio ambiente socioeconômico, sob certas circunstâncias, pode se tornar ideologia. Esta possibilidade universal de virar ideologia está ontologicamente baseada no fato de que o seu conteúdo [...]" - e, não raramente, sua forma também -, "conserva dentro de si as marcas indeléveis de sua gênese" (LUKÁCS, 2013, p. 465). Para o autor, o antagonismo real das ideologias em confronto "[...] entre si assume as formas mais díspares no curso da história, podendo se manifestar como interpretação de tradições, de convicções religiosas, de teorias e métodos científicos, etc., que, no entanto, constituem sempre antes de tudo meios de luta" (LUKÁCS, 2013, p. 465).

Nessa direção, formulações que constituem o que se pode chamar de "falsa consciência" nem sempre se tornam ideologia ${ }^{1}$. Tais formulações, "[...] podem se converter em ideologia só depois que tiverem se transformado em veículo teórico ou prático para enfrentar ou resolver conflitos sociais, sejam estes de maior ou menor amplitude, determinantes dos destinos do mundo ou episódicos" (LUKÁCS, 2013, p. 467).

Em sendo assim, até mesmo uma verdade real pode ser instrumento para dirimir conflitos sociais e, assim, tornar-se ideologia. Por isso, Lukács (2013, p. 468) considera que "o sentido concreto de ideologia [...] é mais amplo do que o do conceito estrito de ideologia. Ele significa apenas - de modo aparentemente tautológico - que, no âmbito do ser social, nada pode ocorrer cujo nascimento não seja decisivamente determinado por esse mesmo ser social". Nesse sentido, levando em conta a estruturação da vida cotidiana, 
Lukács (2013, p. 470) afirma que é nesse espaço que se mostra mais nitidamente o que se pode entender por ideologia, no sentido mais amplo do termo, pois "[...] a vida de cada homem e, em consequência, todas as suas realizações, sejam elas práticas, intelectuais, artísticas etc., são determinadas, no final das contas, pelo ser social em que o referido indivíduo vive e atua".

Assim, se as ideologias servem para que os homens, ao tornarem-se conscientes, determinem-se no sentido de solucionar conflitos sociais, a existência daquelas têm como pressuposto, também, a existência destes. Mais, se os homens singulares são os portadores dos conflitos, isso se deve ao fato de serem eles, também, ontologicamente, "[...] os portadores imediatos de toda a atividade social [...]" (LUKÁCS, 2013, p. 471).

Na imediatidade da vida concreta, diz Lukács (2013, p.471), os conflitos mostram-se como confronto de interesses singulares ou, então, como oposição entre esses interesses singulares e os coletivos, ou, ainda, entre interesses de grupos humanos distintos. Dessa maneira, os próprios grupos humanos formam-se a partir de indivíduos singulares que entre si possuem interesses mais ou menos próximos e que, ao mesmo tempo, se mostram antagônicos aos interesses de outros grupos sociais. Nesse contexto, já é possível verificar, em sentido mais geral, o surgimento de ideologias, haja vista que, segundo o autor, tais

[...] antagonismos só podem ser enfrentados eficazmente na sociedade quando os membros de um grupo conseguem convencer a si mesmos de que seus interesses vitais coincidem com os interesses importantes da sociedade como um todo, portanto, de que cada um daqueles que defende esses interesses, simultaneamente faz algo útil para a sociedade como um todo. Se isso é imposto com os meios do convencimento, com violência franca ou dissimulada, resulta nuanças importantes, mas não é decisivo para sua determinidade como ideologias, assim como tampouco o é a pergunta se o conteúdo corresponde aos fatos sociais, às tendências da época ou está em contradição com eles, se a conviç̧ão que norteia a ação ideologicamente determinada nos homens singulares e em seus grupos é sincera ou hipócrita etc. Esses pontos de vista são de importância decisiva para a apreciação histórico-social concreta das ideologias singulares, mas não constituem uma característica determinante da ideologia em termos gerais (LUKÁCS, 2013, p. 471-472).

Assim, o surgimento das ideologias pressupõe uma determinada estrutura social constituída por diferentes grupos portadores de interesses antagônicos, e cada qual age no sentido de fazer com que seus interesses sejam assimilados como sendo os de toda a sociedade. Conforme Lukács (2013, p. 472), "[...] o surgimento e a disseminação de ideologias se manifestam como a marca registrada geral das sociedades de classe". Adverte o mesmo autor, no entanto, que essa análise, em termos gerais, está correta, mas

[...] essa determinação só pode se tornar um motor da práxis quando os homens singulares vivenciam esses interesses como seus próprios e tentam impô-los no quadro das relações vitalmente importantes para eles com outras pessoas (LUKÁCS, 2013, p. 472).

No modo de produção capitalista, a produção da riqueza é expropriada de quem a produz de maneira a garantir a acumulação da classe detentora dos meios de produção. Em face dos conflitos de classe decorrentes dessa forma de organização da produção, surge uma teleologia jurídica que, mesmo caracterizando-se como um sistema marcado pela incongruência entre suas representações e a realidade econômica, tem a função de regular juridicamente o intercâmbio social entre os homens.

No processo de complexificação social o direito acaba por adquirir uma relativa autonomia, permitindo-Ihe fornecer explicações "plausíveis" para a existência de normas que são contraditórias entre si e, muitas vezes, só aparentemente, parecem estar desconectadas dos interesses hegemônicos. Essa relativa autonomia ou destacamento do direito em face da estrutura econômica e das relações sociais que aí têm origem acaba por obscurecer os processos de exploração do trabalho e a coisificação dos homens, ou seja, a reificação por meio da universalização da forma mercantil. E, é na igualdade formal garantida 
pelo direito que, no modo de produção capitalista, se viabilizará essa universalização da forma mercantil, com base nos princípios da propriedade privada e da liberdade de contrato, donde portadores individuais de mercadorias estabelecem, de modo volitivo, relações de troca.

O complexo do direito mascara a essência dos fenômenos e, nesse diapasão, por sua função social, constitui-se em uma ideologia cujo objetivo é o de alcançar a sujeição dos homens à estrutura econômica e o encobrimento das lutas de classes, conforme afirma Lukács (2013). Tal posição teleológica desempenha o papel de regular juridicamente os conflitos sociais, portanto.

$\mathrm{Na}$ sociedade de classes, à medida que os interesses se antagonizam, emerge a necessidade de regular as relações sociais pelo direito - diferentemente da natureza daquelas regulamentações que nasciam espontaneamente nas práticas sociais (pela tradição, pelo costume). Essa regulação de natureza jurídica tem como função precípua estabelecer regras que tocam em uma questão central: a forma de dispor do mais-valor produzido a partir da atividade do trabalho. Assim, a forma de organização da produção capitalista, fundada na propriedade privada dos meios e dos resultados do trabalho por uma classe, não pode prescindir de mecanismos que atuem no sentido de sujeitar os não proprietários à sua lógica. À medida que as estratégias de produzir mais-valor pelo trabalho na forma mercadoria se desenvolvem, também novas formas de normatizar o acesso a elas avançam, por meio de garantias jurídicas.

Ainda que as estruturas jurídico-legais sejam portadoras de uma relativa autonomia e que não exista nehuma relação mecânica entre os múltiplos complexos sociais e o complexo econômico, este é entendido por Lukács (2013) como uma mediação para compreender a dinâmica dos complexos sociais que constituem a totalidade social. Ele afirma que seria errado deduzir que esses complexos constituem meras parcialidades determinadas pelo complexo originário da economia (o trabalho), como se simplesmente derivados, deduzidos desse complexo. Cada um deles reage de modo peculiar "[...] aos impulsos que o movimento geral do ser social aciona na economia [...]" (LUKÁCS, 2013, p. 270-272).

À luz das reflexões lukacsianas, podemos perceber por que o direito nos aparece como um aspecto dado da realidade, como um elemento a-histórico. O entendimento imediato que se limita à forma de aparecer desse fenômeno é conformado pela carga ideológica do próprio complexo jurídico. A ultrapassagem dessa perspectiva fenomênica do direito só se efetiva quando conseguimos estabelecer as conexões entre as dimensões da realidade social em sua totalidade na qual está inclusa o próprio fenômeno jurídico. Apreender essa totalidade complexa é imprescindível para compreender como, no solo histórico-social, segundo Lukács (2013, p. 277), ocorre uma "[...] autoconservação de uma essência [...]" que se transforma "[...] em meio à constante mudança". De acordo com Lukács (2013, p. 492, grifo do autor), na "[...] realidade social, os limites entre essência e fenômeno muitas vezes se tornam fluidos [...]" e, por isso, "[...] as diferenças realmente existentes só podem ser constatadas com alguma precisão a posteriori, com o auxílio de análises conceituais, científicas".

Para Lukács (2013), determinadas relações de produção condicionam específicas formas do direito e a inter-relação entre esses complexos "[...] é tão forte na imediatidade do ser social que as pessoas que agem têm de tornar uma objetividade unitária presente nelas para pressuposto ou objeto de seus pores teleológico-práticos". De todo modo, essa conjunção não anula o fato de que constituam complexos distintos do ser social, relativamente autônomos entre si e, tampouco, "[...] impede que as relações de produção, impelidas pelo desenvolvimento das forças produtivas, se modifiquem independentemente do sistema legal e, desse modo, necessariamente imponham a este a codificação total ou parcial ou pelo menos as reinterpretações correspondentes" (LUKÁCS, 2013, p. 492-493).

$\mathrm{Na}$ visão lukacsiana, existe sempre um campo real de atuação onde os pores teleológicos surgem como possibilidades para esse campo exclusivamente, suprimindo, desse modo, qualquer predeterminação. Isso faz com que "[...] a necessidade da essência forçosamente assuma para a práxis dos homens singulares a forma de possibilidade" (LUKÁCS, 2013, p. 494).

Desde uma perspectiva marxiana, segundo Lukács (2013), "[...] os conflitos suscitados pelo desenvolvimento contraditório da economia (o desenvolvimento das forças produtivas como transformação, como explosão das relações de produção) são enfrentados e resolvidos com os meios da ideologia [...]". Além disso, é preciso considerar que "[...] a essência econômica, operante independentemente de qualquer 
vontade humana no que se refere à totalidade da sociedade, isto é, em última análise, ao gênero humano, produz apenas as possibilidades objetivas do progresso real" (LUKÁCS, 2013, p. 495).

Ainda, segundo Lukács (2013, p. 495), tais possibilidades são, ao mesmo tempo, "[...] irresistivelmente necessárias [...]" e "[...] necessariamente progressivas [...]" em direção a uma "[...] forma cada vez mais social do ser social, rumo a um ser-si-mesmo cada vez menos falsificado ontologicamente, mas permanecem, no que se refere ao destino do gênero humano, não obstante, apenas possibilidades objetivas (LUKÁCS, 2013, p. 495-496).

O filósofo húngaro assevera que nesse processo nasce uma contradição fundamental para o desenvolvimento do ser social que "[...] determina a relação entre base e ideologia tanto no cotidiano da reprodução lenta e do desdobramento sucessivo de uma formação, como nas grandes crises que acontecem na passagem de uma formação para a outra" (LUKÁCS, 2013, p. 496).

Ademais, compreender o complexo jurídico e como o direito é entendido pelos assistentes sociais no contexto da realidade brasileira exige um esforço teórico e político que consiga se apropriar desse entendimento e de como os agentes profissionais compreendem também essa realidade, cuja estrutura e dinâmica está condicionada pelas formas de dominação econômica e política da burguesia monopolista atenta à construção de estratégias que garantam a valorização do valor e amenizem os impactos negativos da queda tendencial das taxas de lucro. As ações que permitem controlar os conflitos decorrentes das lutas de classes e neutralizar os tensionamentos provocados pelos processos organizativos dos trabalhadores estão no centro dessas estratégias. É também nesse contexto, na disputa pelo direito de fruição da riqueza socialmente produzida, que se situa o trabalho do assistente social.

\section{Serviço social e as lutas por direitos}

Retomando as afirmações de Marx na Ideologia Alemã, Lukács (2013, p. 496) menciona que no processo de desenvolvimento do ser social a divisão social do trabalho ocorreu, realmente, no momento em que trabalho material e trabalho espiritual também foram apartados. Isso não significa que trabalho espiritual - como momento da divisão do trabalho - nos termos adotados por Marx e Lukács, seja igual à ideologia. Contudo, não há como se negar que existe entre estes dois elementos uma imbricação muito grande. Isso porque, segundo Lukács (2013, p. 496):

[...] o resultado de todo trabalho espiritual pode, em determinadas situações sociais, reverter em ideologia, inclusive a divisão social do trabalho produz ininterruptamente situações em que essa reversão se torna necessária e permanente. Nesses casos, isso se expressa na própria divisão do trabalho. Se ocorrer que uma necessidade social tão permanente de regulação dos problemas que surgem na reprodução da vida venha a ser uma necessidade que se renova com o processo de reprodução, essa espécie de atividade terá se tornado socialmente necessária, o que se expressa no fato de que homens singulares ou grupos inteiros podem fazer dela uma ocupação específica visando à manutenção da vida.

Em face dos desdobramentos e complexidades que se vão constituindo no processo de construção do ser social, algumas atividades parecem ter pouca ou nenhuma relação com a produção, mesmo que sejam indispensáveis para que ela ocorra. E, aí, Lukács (2013) destaca a regulamentação jurídica. Esta também, segundo ele, "[...] nada tem a ver com a produção material em si; entretanto, a partir de um determinado estágio, esta não poderia mais ocorrer sem fricção, sem uma regulamentação jurídica da troca, do intercâmbio etc.", que, para serem executadas, demandam sujeitos que acabam vivendo dessa práxis. Esses homens, assim, garantem a reprodução de suas vidas, em termos individuais e genéricos, sem que, para isso, tenham de participar diretamente da "[...] produção material imediata da essência". Para que isso ocorra, de acordo com o autor, o ser social deve alcançar um determinado patamar de desenvolvimento no qual seja possível garantir a reprodução daquele estrato de homens, "[...] o que não seria possível sem 
uma diminuição do tempo de trabalho socialmente necessário para a reprodução na produção imediata". Somente quando a sociedade, por exigência do seu próprio desenvolvimento, faz surgir especialistas jurídicos que vivem de suas atividades realizadas na esfera da reprodução é possível entender o direito como ideologia específica (LUKÁCS, 2013, p. 497).

No nosso ponto de vista, nesse contexto, tornando mais elástica a afirmação lukacsiana sobre o surgimento e a função do direito e das estruturas jurídicas com seus especialistas, podemos situar, também, o serviço social. Isso porque a atuação dos assistentes sociais, historicamente, a partir de diferentes matizes teóricos, sempre esteve implicada com um conjunto de direitos caracterizadores do padrão civilizatório alcançado, ainda que, na realidade brasileira, tal padrão tenha sido sempre muito baixo e marcado mais pela descontinuidade do que pela tendência a sua consolidação progressiva.

De todo modo, o que interessa destacar é que a complexificação do ser social impõe uma diferenciação cada vez maior na divisão social do trabalho, e, para dar respostas aos conflitos que eclodem no processo de constituição permanente desse ser, são "[...] elaborados sistemas interconectados de modo mais ou menos racional [...]" que têm a função de fazer frente e buscar resoluções a tais conflitos, "[...] em conformidade com os interesses da sociedade" (LUKÁCS, 2013, p. 497).

No entanto, é bom que se tenha em mente que, segundo Lukács (2013, p. 497),

[...] quando a estratificação de classes da sociedade se torna realidade, esses interesses coincidem tendencialmente com os da classe dominante naquele momento. E a expressão "tendencialmente" leva justamente ao centro dos problemas da luta de classes, porque seu conteúdo é, em um número muito grande de casos, a decisão sobre como, segundo princípios etc. se constituirá o modo generalizado de dirimir os conflitos (Pense-se nas lutas pelo direito de greve).

Dessa forma, se admitirmos que o direito constitui uma resposta para que problemas e conflitos sejam solucionados no interior da sociedade, e se tais respostas são elaboradas "tendencialmente" em consonância com os interesses dominantes, fica mais clara a avaliação de Lukács $(2013$, p. 501) para quem os juristas são justamente os que apresentam "[...] maiores resistências contra uma apreensão ontologicamente correta das ideologias [...]". Nota-se, aí, novamente, que não há nenhum determinismo nas reflexões trazidas pelo autor. Ao afirmar a vinculação do direito aos interesses dominantes, aponta tal vinculação como uma "tendência". Mostra, portanto, um campo de possibilidades que pode gerar processos sociais que fujam ao controle das classes dominantes e dirigentes. Isso, como sabemos, vale também para o serviço social, tanto que a categoria expressa sua oposição aos interesses hegemônicos em seu projeto ético-político, cujos valores e princípios colidem com a perspectiva de manutenção da sociedade de classes. O serviço social é, pois, também um campo de disputas, cuja direção social é definida a partir das correlações de forças que se travam no interior da profissão, mas que retratam também as lutas e os antagonismos presentes na sociedade brasileira ${ }^{2}$. Assim, também o que se entende por "direitos", o alcance e os limites desses "direitos" na dinâmica das classes em confronto estão diretamente relacionados aos projetos societários em disputa e que repercutem na formulação de diferentes projetos profissionais.

Apoiando-se nas discussões de Engels, Lukács (2013) pondera que o direito se constitui em um sistema internamente coerente porque, em outras palavras, não se boicota explicitando suas contradições. Contudo, sua estruturação e essa "coerência" são "[...] construídos de modo a se tornarem apropriados para enfrentar e resolver conflitos no sentido da sociedade existente em cada caso concreto, no sentido das proporções de poder de classe existentes em cada caso, no patamar da universalidade mais elevada possível em cada caso" (LUKÁCS, 2013, p. 498). Em virtude disso, então, podemos dizer que o direito tendencialmente acaba por provocar, progressivamente, espelhamentos não fidedignos das relações econômicas e, ainda, assim, tais espelhamentos falsos podem ser apropriados "[...] para exercer funções sociais bem determinadas" (LUKÁCS, 2013, p. 498).

Ao discorrer sobre essas "distorções" relacionadas à realidade social feitas a partir de pores jurídicos, o autor evidencia que, no âmbito do direito, há um predomínio da lógica formal que nega a existência de contradições, o que leva os próprios juristas a "[...] formar um falso conhecimento da estrutura do ser social 
que daí resulta" (LUKÁCS, 2013, p. 499). Se nossa compreensão dos ensinamentos do autor estiver correta, podemos dizer, então, que a conexão do direito com a objtividade social pouco importa, pois o que deve prevalecer e determinar as respostas jurídicas são os interesses hegemônicos, vinculados, portanto, aos interesses da classe dominante. É exatamente nessa direção que tais respostas devem propor formas bem determinadas de regulação de conflitos, de modo a resolvê-los (LUKÁCS, 2013, p. 499).

Estas reflexões do autor nos permitem pensar a própria atuação dos profissionais de serviço social, haja vista que comumente, no cotidiano da intervenção, normas e regras jurídicas traduzidas em leis em sentido amplo, são tomadas como fundamento para as decisões relativas às demandas que se apresentam nos diferentes contextos sócio-ocupacionais. Muitas vezes, os profissionais partem do pressuposto de que as normativas legais e institucionais são adequadas às necessidades dos usuários e, mais, são os parâmetros certos para "medir" o acesso aos direitos definidos socialmente. Constrói-se, asim, uma convicção e um consenso conservador sobre o que é direito (aquilo que está positivado) e o que não é direito (não previsto em normativas ou mesmo quando previsto não alcança determinados sujeitos excluídos por critérios de elegibilidade, sob o auspício da "equidade") e, ao mesmo tempo, são abstraídos os antagonismos de classes e as determinações da realidade. O mito da "imparcialidade", assim como o é na área jurídica, impõe-se de tal modo que a intervenção profisional deve ser orientada por um conhecimento técnico irrefutável, mesmo que tal tecnicismo seja funcional aos interesses das classes hegemônicas e pouca ou nenhuma conexão tenha com os ideais de justiça - mesmo que burguesa - e com as necessidades sociais dos usuários.

Conforme já mencionamos, para Lukács $(2013$, p. 500) "[...] a diferenciação da divisão social do trabalho criou simultaneamente à doutrina do direito também os juristas profissionais". E só em virtude disso, segundo o autor, "[...] se consuma o tipo de ser específico do direito como ideologia, ao passo que muitas formas ideológicas importantes, como costume, convenção etc. surgem espontaneamente".

As divergências ideológicas entre o direito e a realidade econômica advindas das elaborações jurídicas são progressivamente acentuadas em virtude de esses especialistas (juristas profissionais) pretenderem "[...] conferir o maior peso possível à sua atividade no complexo total" (LUKÁCS, 2013, p. 501). Utilizando-se das explicações de Engels, Lukács (2013, p. 501) considera que, exatamente porque a atividade jurídica "[...] retroage 'novamente' sobre a base econômica, podendo modificá-la dentro de certos limites, o ponto de vista especificamente ideológico experimenta intensificações ininterruptas [...]", de tal maneira que "[...] o conteúdo e a forma do direito muitas vezes aparecem petrificadas de modo puramente fetichista como forças da humanidade". E, nesse diapasão, facilmente a forma fenomênica é tomada como se a essência fosse, e, assim, "[...] a luta real dos homens reais por sua existência é posta em segundo plano como desprezível submundo da existência" (LUKÁCS, 2013, p. 501). De acordo com Lukács (2013, p. 501):

O caráter real do direito só pode ser evidenciado, portanto, quando se compreende essa deformação glorificadora com aquilo que ela de fato é, a saber, uma ideologização da ideologia, que surge necessariamente quando a divisão social do trabalho delega sua manutenção a um estrato de especialistas.

Ao fim e ao cabo, contudo, é preciso compreender que o direito, para converter-se em instrumento eficaz de resolução de conflitos na perspectiva dos interesses da classe hegemônica, deve apresentar-se como universalidade, não podendo, evidentemente, constituir-se como meio de reprodução autêntica da realidade. Sob o prisma da ideologia, o importante é saber se esse ser específico consegue exercer a função de regular a vida, do ponto de vista social e econômico, de maneira que responda aos conflitos surgidos no processo de desenvolvimento do ser social. Tais respostas precisam ser universalizantes no sentido de que tenham eficácia e validez para todos indistintamente. E, em virtude dessa declarada universalidade de suas respostas, encobre as desigualdades concretas de homens concretos no cotidiano da vida.

Se isso é válido para o direito como complexo social derivado, como sistema ideológico que se constitui a partir daquelas funções reguladoras das relações sociais e das respostas aos conflitos, é também válido para outros complexos a ele mais ou menos vinculados, como é o serviço social. O trabalho do assistente social, no contexto do trabalho social total, está intimamente conectado ao direito e, embora não seja um seu elemento interno, estabelece com ele recíprocas relações que acabam por dar materialidade às teleologias 
que circunscrevem essas duas áreas. Assim como o direito, o serviço social se apresenta como mediação importante nos processos de resolução de conflitos sociais que se manifestam de diferentes formas, mas que têm raízes na dialética dinâmica do desenvolvimento do ser social, envolvendo essência e fenômeno.

O serviço social, por certo, não é portador de uma imagem social homogênea, mas é possível afirmar que é reconhecido pela defesa intransigente de um conjunto significativo de direitos dos trabalhadores. A categoria historicamente esteve envolvida na luta pela saúde pública, pela constituição e expansão da política pública de assistência social, pelo acesso à justiça, por moradia, por educação, por transporte público, pela democratização das decisões em torno dos conteúdos e do desenho das diferentes políticas sociais com vistas a fortalecer o controle social, etc., revelando-se uma profissão que se constrói nos próprios processos dessas lutas. Tudo isso não é pouco. Contudo, a grande questão é saber se na atuação profissional dos assistentes sociais, nos mais diversos espaços de trabalho, essas lutas têm sido articuladas às lutas mais amplas da classe trabalhadora. $E$, ampliando o espectro da análise, nos importa indagar: os profissionais têm conseguido articular essas e outras lutas parciais (pelo uso racional dos recursos naturais, pela igualdade de gênero, contra a LGBTfobia, contra o racismo etc.) à luta de classes, fazendo o confronto com as estruturas e a dinâmica da forma social vigente?

Nesse sentido, a hipótese de trabalho que aqui tomamos como referência consiste na ideia de que os assistentes sociais têm pautado a intervenção profissional muito mais em normas legais (constituição federal, leis, decretos, resoluções, normativas institucionais etc.) do que em teorias sociais que tenham o potencial de dar sustentação ao projeto ético-político defendido pela categoria. Dito de outro modo, os assistentes sociais têm feito das normas legais fundamento da prática em detrimento daquilo que, de fato, é fundamento do trabalho profissional. Essa perspectiva desconsidera a advertência marxiana de que "o direito é o reconhecimento oficial do fato" (MARX, 1985), quer dizer, é a forma jurídica formulada pelo Estado para regular a realidade na qual as relações sociais se processam. Abstrai-se nos processos teleológicos construídos no trabalho profissional o fato de que esse Estado é burguês e que, em última instância, sempre se coloca na defesa dos interesses da classe econômica e politicamente dominante. Acreditamos que essa postura pouco crítica diante da realidade explica em grande parte os dilemas vividos pela profissão, mas nos instiga a reverter este quadro para encontrar alternativas de enfrentamento à barbárie, questão tão bem traduzida nos termos usados por José Paulo Netto (2015, p. 242):

[...] o projeto ético-político profissional do Serviço Social brasileiro não dispõe de nenhuma garantia. É um projeto que, convertido em processo teórico-prático, nestes chamados tempos de incertezas, condensa em torno de seus valores um consenso que aposta em algumas convicções e umas poucas certezas. Mas estas são absolutamente necessárias, porque é em tempos como estes que o esforço para escapar a perplexidades e por encontrar alternativas se converte em estratégia contra a barbárie.

Sem entrar nas polêmicas a respeito da existência ou não de uma crise do projeto hegemônico do serviço social, fato é que, apesar das resistências que marcam o tempo presente, temos enfrentado um importante avanço do pensamento conservador em todas as dimensões da vida social e que repercute diretamente no interior da profissão. Este avanço tem se materializado em formulações muito comuns na produção teórica e técnico-acadêmica do serviço social que questionam ou que afirmam a incapacidade da teoria social crítica, notadamente a de matriz marxiana e marxista, de "dar respostas" às demandas profissionais. Refuta-se, no bojo dos argumentos dessa natureza, o próprio conhecimento ontológico da realidade, em uma perspectiva de totalidade.

Em sendo, de fato, o direito positivado o elemento por excelência norteador do trabalho profissional, há que se considerar que aquele complexo constitui, sim, conforme nos ensina Lukács (2013), respostas aos interesses hegemônicos, ainda que, por outro lado, tais respostas sejam permeáveis às contradições próprias da ordem burguesa e possibilitem simultaneamente o atendimento de determinadas necessidades dos trabalhadores.

O que se pretende aqui enfatizar é que, caso os assistentes sociais reforcem a tendência de fazer do aparato jurídico-legal disponível o "fundamento" privilegiado do trabalho profissional - mesmo que este 
tenha sua importância tática na luta pela defesa de direitos sociais - estarão aprisionados no âmbito da luta pela emancipação política, que, embora necessária, é insuficiente para dar concretude a um projeto societário emancipador.

Nos escritos da Crítica da filosofia do direito de Hegel, Marx (2010, p. 151, grifo do autor) afirma que

A arma da crítica não pode, é claro, substituir a crítica da arma, o poder material tem de ser derrubado pelo poder material, mas a teoria também se torna força material quando se apodera das massas. A teoria é capaz de se apoderar das massas tão logo demonstra ad hominem, e demonstra ad hominem tão logo se torna radical. Ser radical é agarrar a coisa pela raiz. Mas a raiz, para o homem, é o próprio homem.

E, como procuramos demonstrar à luz do pensamento lukacsiano, o direito tende a ser instrumento de dominação de classe, configurando uma mediação de natureza ideológica para resolver conflitos surgidos no processo de desenvolvimento do ser social, com vistas à reprodução da forma social capitalista. Nesta direção, ao refletirmos sobre os desafios impostos ao serviço social pela realidade do capitalismo brasileiro no tempo presente - marcada por uma ofensiva constante e intensa sobre os direitos sociais - temos a prova cabal de que as conquistas que compõem o acervo desses direitos não são perenes. A cada novo ciclo de crise capitalista essas conquistas tendem a ser suprimidas ou reduzidas com vistas a criar contratendências à queda das taxas de lucro dos capitalistas. Nesses momentos, nem mesmo princípios essenciais do próprio direito burguês se sustentam - como o princípio da proibição do retrocesso social ${ }^{3}$ - e, como afirma Marx (2013, p. 309), no contexto da sociedade de classes onde vigora uma igualdade formal e onde as desigualdades reais são abstraídas, no confronto entre direitos iguais, "quem decide é a força".

O próprio Marx já havia advertido em escritos anteriores à sua obra mais importante ( $O$ Capital), ao se deparar com o que ele mesmo chamou de "questões materiais", sobre as ilusões construídas a partir dos ideais de uma universalidade abstrata do direito burguês. Isso ocorre quando ele se posiciona nos seus artigos da Gazeta Renana (em 1842) a favor da população pobre em face da proibição de uma prática consolidada pelo costume: a coleta de madeira das florestas ${ }^{4}$. Esse direito surgido dos costumes dos pobres entra em oposição com o direito legal dos ricos proprietários, a partir da positividade de uma norma que punia os que "roubavam" madeira das propriedades privadas. Essa lei revelava, segundo Marx (2017), quão frágil é a ideia da universalidade do Estado (e do próprio direito burguês), na medida em que este transformava o interesse burguês em interesse geral, desconsiderando as necessidades e os hábitos dos pobres que, em essência, revelavam o "instintivo sentido do direito". Assim, a universalidade abstrata do direito burguês se apresenta como tal pela permanência e prevalência dos interesses particulares das classes dominantes em relação aos interesses das classes pobres, quase sempre tratados como privilégios a serem desconstruídos. Do ponto de vista do trabalho do assistente social, não raramente a defesa da norma instituída ou a defesa da positivação de direitos implica a negação das próprias necessidades dos trabalhadores, pois, no interior da sociedade de classes, os conteúdos dos direitos são delimitados pela oposição aos interesses do capital.

Da constatação dos limites do trabalho profissional do assistente social no âmbito da sociedade de classes e de sua relação com o direito burguês na tentativa de potencializar o acesso dos usuários dos serviços sociais à riqueza produzida não pode reinar nenhum determinismo. Essa advertência nos desafia a pensar a necessária conexão das lutas travadas pelo serviço social para a criação, defesa e ampliação de direitos com a luta pela emancipação humana. A questão é que nem sempre a luta por direitos constitui uma luta anticapitalista, levando os assistentes sociais a se tornarem reféns das ilusões alhures mencionadas por Marx. Nesse sentido, acabam por contribuir para a reprodução das relações sociais capitalistas, haja vista que em suas ações cotidianas reafirmam processos que resultam na sujeição formal e real dos trabalhadores ao capital. Isso, no nosso ponto de vista, está relacionado ao fato de que, ao responder as demandas do mercado de trabalho sem submetê-las ao crivo da crítica baseada em uma racionalidade substantiva (GUERRA, 2014), os assistentes sociais têm trilhado caminhos que reificam a técnica, os procedimentos burocráticos e os fluxos institucionais - preocupados em parecer e ser competentes do ponto de vista do 
mercado de trabalho - em detrimento do desenvolvimento da capacidade de desvelar a processualidade histórica daquelas demandas, com vistas a atender as reais necessidades dos trabalhadores. Tal postura afasta-os, progressivamente, do campo crítico e do projeto profissional construído desde as últimas décadas do século XX. A reversão dessa tendência só pode ocorrer por meio do mesmo mecanismo que construiu os processos que alinharam o serviço social brasileiro às perspectivas críticas: a luta política da categoria conectada à luta dos movimentos dos trabalhadores e à apropriação da realidade por meio do método desenvolvido por Marx, haja vista que este é o método capaz de desvelar a processualidade histórica e social.

\section{Considerações finais}

Sim! "Nenhum direito a menos". No entanto, nossas organizações político-acadêmicas, nossas programáticas de atuação nos espaços de trabalho e de formação precisam ser orientadas a partir dos pressupostos da teoria social crítica capazes de nos permitir superar as explicações rasas que captam apenas a aparência dos fenômenos sociais. É preciso contribuir para que o novo, de fato, seja novo e não uma reinvenção do velho que faz perpetuar as estruturas sociais que geram as ilusões que ainda habitam nossos corações e mentes em relação às possibilidades da profissão no contexto das lutas por direitos na ordem regida pelo capital, especialmente no contexto da sociedade brasileira, onde as forças políticas ultraconservadoras têm revigorado o discurso do ódio contra os pobres e outras minorias. Para que o serviço social consiga avançar em seu compromisso ético e político com a construção de uma sociedade sem exploração de classe e sem quaisquer formas de dominação é preciso abandonar as narrativas abstratas sobre direitos (e seus princípios) que encobrem os antagonismos de classe e absorvem apenas parcialmente as necessidades reais dos trabalhadores. Ademais, no horizonte da luta pela emancipação política, tais direitos são sempre reduzidos ou suprimidos em face da intensificação das crises capitalistas. Isso denota que a luta pelos direitos é sempre necessária, mas o farol orientador do trabalho do assistente social é o projeto de emancipação humana. Para navegar nessa direção, mais do que o domínio das normativas jurídicas que regulam direitos - nunca perenes -, é preciso que os profissionais se apropriem da realidade social na qual são engendrados os processos sociais que dão origem a tais normativas com vistas a controlar os conflitos de classe e reproduzir as relações sociais próprias do modo de produção capitalista. A apropriação dessa dinâmica é essencial para que as respostas formuladas pela profissão em face das demandas a ela apresentadas sejam convergentes com a negação da ordem societária que subjuga os interesses dos trabalhadores aos interesses do capital.

\section{Referências}

BENSAÏD, Daniel. Apresentação. os despossuídos: Karl Marx, os ladrões de madeira e o direito dos pobres. In: MARX, Karl. Os despossuídos. São Paulo: Boitempo, 2017.

FONTES, Virgínia. O Brasil e o capital-imperialismo: teoria e história. Rio de Janeiro: EPSJV/Fiocruz; Editora UFRJ, 2010.

GUERRA, Yolanda. A instrumentalidade do serviço social. 10. ed. São Paulo: Cortez, 2014.

LUKÁCS, György. Para uma ontologia do ser social II. São Paulo: Boitempo, 2013.

NETTO, José Paulo. O projeto ético-político profissional do serviço social brasileiro. Revista Intervenção Social, Lisboa, n. 42/45, p. 229-242, 2015. Disponível em: http://repositorio.ulusiada.pt/bitstream/11067/1734/1/IS_42-45_13.pdf. Acesso em: 25 abr. 2017.

MARX, Karl. Os despossuídos: debates sobre a lei referente ao furto de madeira. São Paulo: Boitempo, 2017.

MARX, Karl. O Capital: crítica da economia política [Livro I: o processo de reprodução do capital]. São Paulo: Boitempo, 2013 
MARX, Karl. Crítica da filosofia do direito de Hegel. São Paulo: Boitempo, 2010.

MARX, Karl. A miséria da filosofia. São Paulo: Global, 1985.

SARLET, Ingo Wolfgang. Notas sobre a assim designada proibição de retrocesso social no constitucionalismo latinoamericano. Revista do TST, Brasília, v. 75, n. 3, p. 116-149, jul./set. 2009. Disponível em: http://aplica-cao.tst.jus.br/dspace/ bitstream/handle/1939/13602/007_sarlet.pdf?se-quence=4. Acesso em: 23 abr. 2017.

\section{Notas}

${ }^{1}$ Em outra passagem, Lukács (2013, p. 480) assevera: "com certeza é correto dizer que a esmagadora maioria das ideologias se baseia em pressupostos que não conseguem resistir a uma crítica rigorosamente gnosiológica, especialmente quando esta toma como ponto de partida um intervalo vasto de tempo. Neste caso, porém, trata-se de uma crítica da falsa consciência; contudo, em primeiro lugar, há muitas realizações da falsa consciência que jamais se converteram em ideologias e, em segundo lugar, aquilo que se converteu em ideologia de modo algum é necessária e simplesmente idêntico à falsa consciência. Por essa razão, só é possível compreender o que realmente é ideologia a partir de sua atuação social, a partir de suas funções sociais".

2 Para essa discussão remetemos o leitor ao instigante livro de Virgínia Fontes intitulado O Brasil e o capital-imperialismo: teoria e história. Rio de Janeiro: EPSJV/Fiocruz; Editora UFRJ, 2010.

${ }^{3}$ Esse princípio jurídico está relacionado à ideia de irreversibilidade dos direitos fundamentais. Segundo Sarlet (2009, p. 123), em seu sentido mais amplo, tal princípio significa "[...] uma proteção dos direitos contra medidas de cunho restritivo, a todos os direitos fundamentais". O mesmo jurista assevera: “[...] se o manejo constitucionalmente adequado e responsável do princípio da proibição do retrocesso (que definitivamente não se presta a blindar privilégios injustificáveis, pelo simples fato de terem sido, em determinado contexto, assegurados a certos grupos de pessoas) não constitui certamente a única via para proteger os direitos fundamentais sociais, também não restam dúvidas de que se trata de uma importante conquista dogmática jurídico-constitucional [...] para assegurar, especialmente no plano de uma eficácia negativa, a proteção dos direitos sociais contra a sua supressão e erosão pelos poderes constituídos, ainda mais em um ambiente marcado por acentuada instabilidade social e econômica, como é o caso - também - do espaço latino-americano (SARLET, 2009, p. 149).

${ }^{4} \mathrm{Na}$ apresentação do livro Os despossuídos (2017), Daniel Bensaïd contextualiza a prática da coleta da madeira e de outros produtos florestais que eram usados para produção de vassouras, conserto de utensílios domésticos, para fazer ripas de telhados, para edificar escadas, como insumo para aquecimento (lenha) etc. De acordo com o autor, Marx evidencia que o aumento do "furto" da madeira revelava o pauperismo da população rural. A criação de uma legislação que punia a prática costumeira da coleta desses materiais respondia aos interesses dos proprietários diante do "[...] fato de que a integração da madeira no circuito de criação de valor comercial torna seu valor de uso e seu valor de troca indissociáveis. O desafio da nova legislação é fazer valer o direito de propriedade, distinguindo com rigor os títulos de propriedade dos títulos de necessidade, a economia de troca da economia de subsistência" (BENSAÏD, 2017, p. 16-17).

Recebido em: 10/4/2019.

Aprovado em: 12/4/2019.

Publicado em: 10/10/2019.

Correspondência para:

Jaime Hillesheim

Universidade Federal de Santa Catarina

Campus Reitor João David Ferreira Lima - Trindade

88040-900, Florianópolis, SC, Brasil

Autor:

JAIME HILLESHEIM

Doutor em Serviço Social pelo Programa de Pós-Graduação em Serviço Social (UFSC).

Professor do Departamento de Serviço Social e Programa de Pós-graduação em Serviço Social,

Universidade Federal de Santa Catarina (UFSC), Florianópolis, SC, Brasil.

Orcid: https://orcid.org/0000-0002-2798-6418

E-mail: jaime.h@ufsc.br 